\title{
Cultured Brain Microvessel Endothelial Cells as In Vitro Models of the Blood-Brain Barrier
}

\author{
Yoshinobu Takakura, Kenneth L. Audus, \\ and Ronald T. Borchardt
}

INTRODUCTION

A central nervous system (CNS) site of action generally requires that, following entry into the systemic circulation, substances must interact with the blood-brain barrier (BBB) en route to brain tissue targets. Many substances with CNS activity, including drugs of abuse, cross the BBB by simple passive diffusion (Oldendorf 1974; Levin 1980; Cornford et al. 1982). Accordingly, the BBB plays an important role in regulating access of drugs of abuse to the brain.

Recent evidence suggests that some drugs of abuse may alter BBB permeability characteristics. The permeability-altering activity of drugs of abuse at the BBB has been reported in chronic amphetamine intoxication (Rakic et al. 1989), acute ethanol exposure (Gulati et al. 1985), and opiate treatment (Baba et al. 1988). Ethanol addiction also has been reported to alter opiate interactions with the transport systems of the BBB (Banks and Kastin 1989). On the basis of these reports, one might infer that interactions of drugs of abuse with the BBB may have implications for the observed pharmacological and toxicological manifestations of exposure to these substances. These implications remain to be explored and confirmed. Consequently, the development of a fundamental understanding of the permeability and metabolic features of the BBB may contribute to a broader knowledge of the activity of drugs of abuse In the CNS.

The complexity of the whole animal as an experimental model has certain limitations when specific events at the cellular or molecular level are examined. In vitro models (i.e., brain microvessel suspensions or cultured brain endothelial cells) offer a promising alternative for the investigation of cellular- or molecularlevel characteristics of the BBB (Audus et al. 1990; Audus and Borchardt 1987). The purpose of this chapter is to describe studies of the transport 
and metabolism characteristics of the BBB that employ cultured brain microvessel endothelial cells as in vitro BBB models. This chapter does not describe isolated suspensions of brain microvessel endothelial cells as in vitro models, since this subject has been reviewed by Betz and Goldstein (1984) and more recently by Takakura and coworkers (1991 a). In addition, this chapter does not describe how cultured brain microvessel endothelial cells have been used to study the development and regulation of the BBB and pathological changes in the BBB, since these topics are discussed in other chapters in this monograph and have been reviewed previously by Takakura and coworkers (1991 a).

\section{ESTABUSHMENT AND CHARACTERIZATION OF CULTURED BRAIN MICROVESSEL ENDOTHELIAL CELLS AS IN VITRO BBB MODELS}

Since Panula and colleagues (1978) demonstrated that rat brain microvessel endothelial cells could be maintained in tissue culture, various kinds of both primary and passaged cultures of isolated brain microvessel endothelial cells have been established from mouse, rat, bovine, human, canine, and porcine brain (for a review, see Audus et al. 1990).

In general, either enzymatic or mechanical dispersal, or a combination of both techniques, followed by either filtration or centrifugation steps are employed to isolate a homogeneous population of brain microvessel endothelial cells from the extremely heterogeneous population of cells found in brain tissues. For example, isolation of a viable, homogeneous population of brain capillary endothelial cells for establishment of a tissue culture system is accomplished by a two-step enzymatic digestion with dispase and a dispase/collagenase mixture of cerebral gray matter and successive centrifugation over dextran and percoll gradients (Bowman et al. 1983; Audus and Borchardt 1986a, 1987). In the authors' laboratories, primary cultures of bovine brain microvessel endothelial cell monolayers have been shown to retain morphological and biochemical properties typical of the BBB in vivo. These include tight junctions, attenuated pinocytosis, lack of fenestra, and the presence of proteins (e.g., yglutamyl transpeptidase, alkaline phosphatase, angiotensin-converting enzyme, factor VIII antigen) enriched in the endothelium of the BBB (Audus and Borchardt 1986a, 1987).

Basically, two types of experimental systems have been employed for study of transport phenomena using cultured brain microvessel endothelial cells: The first is the uptake study, and the second involves a transcellular transport study. The former system uses microvessel endothelial cell monolayers grown in culture dishes (Scriba and Borchardt 1989a, 1989b). Uptake experiments can be performed also using cerebral microvessel endothelial cells cultured on 
microcarriers (e.g., dextran beads) (Bottaro et al. 1986; Kempski et al. 1987). These systems allow examination of the first step of the transport process, that is, the uptake of the solutes into the brain capillary cells from the luminal side. The most sophisticated in vitro system for transport studies consists of cultured brain microvessel endothelial cell monolayers grown on microporous membranes. Transport studies can then be conducted in side-by-side diffusion cells or the cell-insert system (Audus et al. 1990). These systems afford an opportunity to look at bidirectional transendothelial movement (transfer from brain to blood and that from blood to brain) of solutes across the BBB in vitro since, at least for primary cultures of bovine microvessel endothelial cells, the cells are shown to be morphologically and functionally polarized in terms of ricin recycling (Raub and Audus 1990), transferrin transport (Newton and Raub 1988), and angiotensin II (Ang II) responsiveness (Guillot and Audus 1990, 1991a). The purity of these monolayers is greater than 95 percent (Gurllot et al. 1990). and the transelectrical resistance is $160 \pm 18 \mathrm{ohm} / \mathrm{cm}^{2}$ (T.J. Raub, unpublished results).

Although bovine brain microvessel endothelial monolayers retain tight junctions, the tight junctions are not identical to those observed in vivo with regard to extent and complexity. This leads to higher leakiness in vitro than in vivo, which is a disadvantage in the use of cultured endothelial cells alone to study transcellular transport.

More impermeable monolayers of cultured brain microvessel endothelial cells may be developed in the future by exploiting the regulatory role of astrocytes in endothelial cell growth and development. It is widely accepted that the brain microvessel endothelial cells in vivo form the structural and functronal bases of the BBB; however, some of the BBB functions are known to be regulated by astrocytes, which encircle the microvessel endothelial cells with their foot processes In vivo. Similar regulatory effects of astrocytes on the permeability properties of cultured endotheltal cells in vitro have been reported. For example, Cancilla and DeBault (1983) demonstrated that contact with glial cells (a rat line of neoplastic astrocytes designated as C6 glioma cells) or exposure to glial-conditioned media enhances neutral amino acid uptake by passaged mouse cerebral endothelial cells in culture. Conditioned media prepared from astrocytes and C6 glioma cells have been shown to stimulate glucose uptake in passaged mouse cerebral endothelial cells (Maxwell et al. 1989) and in primary cultures of bovine brain microvessel endothelial cells (Takakura et al. 1991 b). Conditioned media from rat astrocytes or C6 glioma cells also ,have been shown to decrease the permeability of various solutes across monolayers of bovine brain microvessel endothelial cells grown on microporous membranes (Trammel and Borchardt 1989; Raub et al. 1989). Recently, Dehouck and colleagues (1990) observed decreases in permeability 
and increases in electrical resistance using an in vitro model system consisting of passaged brain microvessel endothelial cells grown on one side of a filter and astrocytes on the other side of the filter.

\section{UPTAKE AND TRANSPORT STUDIES}

\section{Nutrients}

Since glucose is an important source of energy for the brain, the mechanism of glucose transport across the BBB has been particularly well studied in vivo (Pardridge 1983). These studies support the concept that glucose is transported through the cerebral microvessel endothelium mainly by the mechanism of carrier-mediated facilitated diffusion. Glucose transport characteristics also were studied in cultured brain microvessel endothellal cells. For example, Vinters and coworkers (1985) demonstrated that the properties of 3-O-methylglucose (3MG) and 2-deoxyglucose uptake in established lines of cultured mouse cerebral microvessel endothelium are similar to those observed in vivo. Recently, characteristics of both uptake and transendothelial transport of 3MG were studied in primary cultures of bovine brain microvessel endothelial cells (Takakura et al. 1991c). The uptake characteristics of $3 M G$ were shown to be identical to those observed in vivo and in vitro using isolated capillaries. Transport rates from the luminal to abluminal side and from the abluminal to luminal side, measured across the brain microvessel endothelial cells grown onto polycarbonate membranes, were nearly identical, suggesting symmetrical glucose transport across the monolayer of endothellal cells.

The passage of amino acids across the BBB was found to be saturable and stereospecific in vivo (Oldendorf 1971). Cancilla and DeBault (1983) showed the presence of $A$ - and L-systems for uptake of neutral amino acids in cultured mouse cerebral endothelial cells. Using primary cultures of bovine brain microvessel endothelial cell monolayers grown onto microporous membranes, transport of a large neutral amino acid, leucine, was shown to be saturable, bidirectional, competitive with other amino acids, and energy independent (Audus and Borchardt 1986b). The kinetic parameters for leucine transport appear to be in good agreement with true kinetic parameters of the in vivo BBB. The transport of several amino acid drugs-including baclofen (van Bree et al. 1988), a-methyldopa (Chastain and Borchardt 1989). and acivicin (Chastain and Borchardt 1990)-by the amino acid carrier also has been explored in this system.

Because of a limited capability for de novo synthesis of choline, an important precursor to acetylcholine and phospholipid, the brain must depend on the 
blood for its supply of choline. Cornford and colleagues (1978) demonstrated the saturability of brain uptake of choline after intracarotid injection in rats. Recently, Estrada and associates (1990) studied choline uptake by bovine cerebral capillary endothelial cells in culture, demonstrating that these cells were able to incorporate choline by a carrier-mediated mechanism. The choline uptake was temperature dependent and was inhibited by choline analogs but was not affected by ouabain or dinitrophenol. Transendothelial transport of choline in cultured bovine brain microvessel endothelial cells has been characterized (Trammel and Borchardt 1987); it has been shown that the transport is saturable and is insensitive to ouabain and sodium azide, suggesting a facilitated diffusion mechanism.

Since the brain is one of the most active tissues for carrying out nucleotide and nucleic acid synthesis, the transport of nucleosides and purine bases across the BBB has been of interest. By employing the intracarotid injection technique in rats, Cornford and Oldendorf (1975) demonstrated the presence of two independent carrier systems for nucleic precursors: a nucleoside carrier and a purine base carrier. Beck and coworkers (1983) have described a carrier-mediated uptake of adenosine into mouse cerebral capillary endothelial cells in tissue culture. Characterization of the nucleoside uptake (e.g., adenosine, thymidine) into monolayers of cultured bovine brain endothelial cells also was studied, and the results suggested the presence of a carriermediated uptake of adenosine and thymidine (Shah and Borchardt 1989). Adenosine uptake is primarily via the carrier-mediated pathway, whereas thymidine enters by both a carrier-mediated and a passive pathway. Both nucleosides are extensively metabolized (e.g., phosphorylated) in the cultured bovine endothelial cells.

\section{Peptides and Proteins}

Although the physiological role of insulin in the regulation of brain functions remains to be elucidated, van Houten and Posner (1979) revealed that blood vessels throughout the CNS of the rat bind plasma insulin rapidly and with considerable specificity in vivo. The binding and receptor-mediated endocytosis of insulin and insulin-like growth factor I (IGF-I) also were studied using cultured bovine brain microvessel endothelial cells (Keller and Borchardt 1987; Keller et al. 1988). Rosenfeld and colleagues (1987) showed the similarity between the characteristics of the specific receptors for IGF-I and insulin-like growth factor II in the cultured bovine brain microvessel endothelial cells and in isolated rat brain microvessels.

Using monoclonal antibodies to the transferrin receptors, Jefferies and coworkers (1984) first reported that rat and human brain capillary endothelia 
have receptors for transferrin, an iron-transport protein in the circulation. Newton and Raub (1988) characterized the transferrin receptor in primary cultures of brain capillary endothelial cells, indicating saturable binding and internalization. They also demonstrated the transcytosis and the polarized efflux of transferrin using brain microvessel endothelial cells grown onto polycarbonate filters; these findings are in good agreement with the in vivo observations of Fishman and coworkers (1987) and Banks and coworkers (1988).

Atrial natriuretic factor (ANF), which is a 28-amino acid peptide produced by cardiac myocytes and released in response to increases in atrial pressure, expresses its natriuretic, diuretic, and hypotensive effects by acting on renal and vascular tissues. A specific receptor for ANF also was identified using primary cultures of bovine brain capillary endothelial cells (Smith et al. 1988). The binding of ANF was specific, saturable, and reversible. ANF also was shown to be rapidly internalized by a temperature-dependent process, A specific receptor for brain natriuretic peptide (BNP), which was found in the brain and has similarity to ANF in its structure and biological activities (Sudoh et al. 1988), was identified recently in primary cultures of bovine brain microvessel endothelial cells (M. Fukuta, M. Nonomura, Y. Takakura, and R.T. Borchardt, unpublished results). These studies suggested that ANF and BNP share the same receptor in bovine brain microvessel endothelium.

Speth and Harik (1985) reported that Ang II binds to microvessels isolated from dog brain in a specific, saturable, and reversible manner and with high affinity. It was suggested that specific Ang II receptor-binding sites are present in brain microvessels and that these receptors may have an important role in regulating the microcirculation of the brain. Work in the authors' laboratories indicates that bovine brain microvessel endothelial cell monolayers retain a high-affinity Ang II binding site that can be competed for by Ang II peptides (Guillot and Audus 1991b).

Recently, the transport of leu-enkephalin across the BBB by a carrier-mediated mechanism has been demonstrated in vivo (Zlokovic et al. 1987). In addition, Thompson and Audus (1989) showed that leu-enkephalin transfer across monolayers of brain microvessel endothelial cells occurs at a relatively high rate, which is consistent with a facilitated diffusion mechanism.

Vasopressin transport across the BBB has been examined with primary cultures of brain microvessel endothelial monolayers (Reardon and Audus 1989). Results suggest the existence of facilitated transport of the peptide from the abluminal to the luminal side of the monolayers. This finding is consistent with the in vivo characterization of a vasopressin BBB transport system (Banks 
et al. 1987). Van Bree and colleagues (1989) also have studied transport of vasopressin using an in vitro system and suggested that no carrier mediation is involved over a higher concentration range. Confirmatory studies are required to clarify the transport mechanism in detail.

Raeissi and Audus (1989) characterized the BBB permeability to delta sleepinducing peptide (DSIP) in cultured microvessel endothelial cells. The results support in vivo observations indicating that intact DSIP crosses the BBB by simple transmembrane diffusion (Banks and Kastin 1987). Recently, Zlokovic and coworkers (1989) presented evidence in support of a facilitative BBB carrier for DSIP in vivo. Further work is ongoing concerning the solution structure of DSIP, which may help to explain its ability to readily penetrate the BBB (Audus and Manning 1990).

Native albumin, which is an acidic protein in plasma, is considered to pass through the BBB very slowly (Pardridge et al. 1985). However, increased BBB uptake and transport recently has been reported when it is chemically modified. Kumagai and colleagues (1987) demonstrated the enhanced binding and adsorptive-mediated endocytosis of cationized albumin by isolated bovine brain capillaries. The binding was saturable and inhibited by other polycations (e.g., protamine, protamine sulfate, and polylysine). Similar results have been reported for other types of polycationic proteins, including cationized immunoglobulin G (Triguero et al. 1989) and histone (Pardridge et al. 1989). Smith and Borchardt (1989) studied the binding, uptake, and transcellular transport of bovine serum albumin (BSA), cationized BSA (cBSA), and glycosylated BSA (gBSA) in cultured bovine brain microvessel endothelial cells. This study demonstrated that cBSA and gBSA bind to the cells specifically and are transported by an adsorptive-phase endocytotic mechanism. The use of cationized albumin in directed delivery of peptides through the BBB was examined by coupling ß-endorphin to cationized albumin via a disulfide linkage (Kumagai et al. 1987).

\section{Drugs}

In contrast to water-soluble nutrients and peptides, which are transported by specific carrier- or receptor-mediated systems as mentioned above, most water-soluble solutes, including drugs, pass through the BBB by a passive diffusion mechanism. From in vivo studies, it has been well established that the permeability of these molecules across the BBB depends directly on their lipophilicity and inversely on their molecular size (Oldendorf 1974; Levin 1980; Cornford et al. 1982). Rim and coworkers (1986) and Shah and coworkers (1989) established a positive correlation between lipid solubility of a drug and its permeability across bovine brain microvessel endothelial monolayers grown 
onto microporous membranes. As mentioned earlier in this chapter, brain microvessel endothelial monolayers are leakier than the BBB in vivo. Therefore, this leakiness in the monolayers must be corrected for by using impermeant marker molecules (e.g., sucrose, fluorescein, inulin, and dextran) when drug transport studies are conducted (Shah et al. 1989).

\section{IN VITRO STUDIES ON BBB METABOLISM}

Several different enzyme systems have been established in primary cultures of bovine brain microvessel endothelial cell monolayers. Both biochemical and histochemical techniques have been used to follow the expression of marker and catecholamine-metabolizing enzymes associated with these monolayers. For instance, enzyme systems considered markers for the BBB, $\boldsymbol{\gamma}$-glutamyl transpeptidase and alkaline phosphatase, and for the endothelium, angiotensinconverting enzyme, are retained in the monolayers (Baranczyk-Kuzma et al. 1986). In addition, the brain microvessel endothelial cell monolayers retain the ability to degrade catecholamines through expression of monoamine oxidases $A$ and $\mathrm{B}$, catechol O-methyltransferase, and phenol sulfotransferase (BaranczykKuzma et al. 1986, 1989a; Scriba and Borchardt 1989a. 1989b). Using monolayers of bovine brain microvessel endothelial cells, the metabolism of catecholamine esters (Scriba and Borchardt 1989a) and of 1-methyl-4-phenyl1,2,3,6-tetrahydropyridine (MPTP) has been studied (Scriba and Borchardt $1989 b)$.

The lysosomal compartment of endothelia is an important component of the transcytosis of macromolecules (Simionescu 1979). Current interest by the pharmaceutical industry in the delivery of therapeutic biotechnology products to the CNS (Audus et al. 1990) suggests a need for considering the activity of the lysosomal compartment of the BBB. However, little work has focused on lysosomal or acid hydrolase compartments within the BBB in vivo. By both quantitative and qualitative measures, bovine brain microvessel endothelial cells possess a lysosomal compartment that expresses typical acid hydrolases, acid phosphatase, B-galactose, and sulfatases (Baranczyk-Kuzma et al. 1989b). Peptidase activity has not yet been examined in the lysosomal fraction; however, aminopeptidase activity is characteristic of membrane and cytosolic fractions of the cells (Baranczyk-Kuzma and Audus 1987). Corresponding quantitative studies in in vivo enzyme systems and compartments have not been performed and may not be feasible. Therefore, the in vitro model may be a reasonable system in which to initiate further studies on the contributions of the lysosomal compartment to the fate of endocytosed peptides and proteins at the BBB (Baranczyk-Kuzma et al. 1989b). 


\section{CONCLUSIONS}

The development of in vitro BBB models consisting of cultured brain microvessel endothelial cells has made possible the study of BBB transport and metabolism phenomena at the cellular level. Basic characteristics of BBB transport and metabolism of endogenous and exogenous solutes and their biochemical, pharmacological, ontogenic, and pathological regulation mechanisms have been investigated. This information has led not only to a better understanding of BBB transport but also to the construction of strategies for improving drug delivery to the CNS for diagnosis and therapeutics. To elucidate the complexity of BBB transport, in vivo studies are always necessary at some point; however, in vitro systems can be useful complements to in vivo systems. The tissue culture systems seem to be especially important in the clarification of cellular, biochemical, and molecular features of BBB transport. Appropriate systems should be selected or combined, depending on the purpose of the investigation.

\section{REFERENCES}

Audus, K.L.; Bartel, R.L.; Hidalgo, I.J.; and Borchardt, R.T. The use of cultured epithelial and endothelial cells for drug transport and metabolism studies. Pharm Res 7:435-451, 1990.

Audus, K.L., and Borchardt, R.T. Characterization of an in vitro blood-brain barrier model system for studying drug transport and metabolism. Pharm Res 3:81-87, 1986a.

Audus, K.L., and Borchardt, R.T. Characteristics of the large neutral amino acid transport system of bovine brain microvessel endothelial cell monolayers. $J$ Neurochem 47:484-488, 1986b.

Audus, K.L., and Borchardt, R.T. Bovine brain microvessel endothelial cell monolayers as a model system for the blood-brain barrier. Ann $N$ Y Acad Sci 507:9-18, 1987.

Audus, K.L., and Manning, MC. In vitro studies of peptide transport through a cell culture model of the blood-brain barrier. Eur J Pharmacol 183:1636$1637,1990$.

Baba, M.; Oishi, R.; and Saeki, K. Enhancement of blood-brain barrier permeability to sodium fluorescein by stimulation of $\mu$ opioid receptors in mice. Naunyn Schmiedebergs Arch Pharmacol 337:423-428, 1988.

Banks, W.M., and Kastin, A.J. Saturable transport of peptides across the bloodbrain barrier. Life Sci 41:1319-1338, 1987.

Banks, W.M., and Kastin, A.J. Inhibition of the brain to blood transport system for enkephalins and Tyr-MIF-1 in mice addicted to or genetically predisposed to drinking ethanol. Alcohol 410:53-57, 1989. 
Banks, WM.; n Kastin, A.J.; Fasold, M.B.; Barrera, C.M.; and Augereau, G. Studies of the slow bidirectional transport of iron and transferrin across the blood-brain barrier. Brain Res Bull 21:881-885, 1988.

Banks, W.M.; Kastin, A.J.; Horvath, A.; and Michals, E.A. Carrier-mediated transport of vasopressin across the blood-brain barrier of the mouse. J Neurosci Res 18:326-332, 1987.

Baranczyk-Kuzma, A., and Audus, K. Characteristics of aminopeptidase activity from bovine brain microvessel endothelium. J Cereb Blood Flow Metab 7:801-805, 1987.

Baranczyk-Kuzma, A.; Audus, K.; and Borchardt, R.T. Catecholaminemetabolizing enzymes of bovine brain microvessel endothelial cell monolayers. J Neurochem 46:1956-1960, 1986.

Baranczyk-Kuzma, A.; Audus, K.; and Borchardt. R.T. Substrate specificity of phenol sulfotransferase from primary cultures of bovine brain microvessel endothelium. Neurochem Res 14:689-691, 1989a.

Baranczyk-Kuzma, A.; Raub, T.J.; and Audus, K. Demonstration of acid hydrolase activity in primary cultures of bovine brain microvessel endothelium. J Cereb Blood Flow Metab 9:280-289, 1989b.

Beck, D.W.; Vinters, H.V.; Hart, M.N.; Henn, F.A.; and Cancilla, P.A. Uptake of adenosine into cultured cerebral endothelium. Brain Res 271:180-183, 1983.

Betz, A.L., and Goldstein, G.W. Brain capillaries: Structure and function. In: Lajtha, A., ed. Handbook of Neurochemistry. Vol. 7. New York: Plenum Press, 1984. pp. 465-484.

Bottaro, D.; Shepro, D.; and Hechtman, B. Heterogeneity of intimal and microvessel endothelial barriers in vitro. Microvasc Res 32:389-398, 1986.

Bowman, P.D.; Ennis, S.R.; Rarey. K.E.; Betz. A.L.; and Goldstein, G.W. Brain microvessel endothelial cells in tissue culture: A model for study of bloodbrain barrier permeability. Ann Neural 14:396-402, 1983.

Cancilla, P.A., and DeBault, L.E. Neutral amino acid transport properties of cerebral endothelial cells in vitro. J Neuropafhol Exp Neural 42:191-199, 1983.

Chastain, J.E., Jr., and Borchardt, R.T. L-œ-methyldopa transport across bovine brain microvessel endothelial cell monolayers, a model of the bloodbrain barrier. Neurosci Res Commun 4:147-152, 1989.

Chastain, J.E., Jr., and Borchardt, R.T. Acivicin transport across bovine brain microvessel endothelial cell monolayers. A model of the blood-brain barrier. Neurosci Res Commun 651-55, 1990.

Cornford, E.M.; Baun, L.D.; and Oldendorf, W.H. Carrier mediated blood-brain barrier transport of choline analogs. J Neurochem 30:299-308, 1978.

Cornford, E.M.; Baun, L.D.; Oldendorf, W.H.; and Hill, M.N. Comparison of lipid-mediated blood-brain barrier penetrability in neonates and adults. Am J Physiol 243:C161-C168,1982. 
Cornford, E.M., and Oldendorf, W.H. Independent blood-brain barrier transport systems for nucleic acid precursors. Biochim Biophys Acta 394:211-21 9, 1975.

Dehouck, M.-P.; Meresse, S.; Delorme, P.; Fruchart, J.-C.; and Cecchelli, R. An easier, reproducible, and mass-production method to study the bloodbrain barrier in vitro. J Neurochem 54:1798-1801, 1990.

Estrada, C.; Bready, J.; Berliner, J.; and Cancilla, P.A. Choline uptake by cerebral capillary endothelial cells in culture. J Neurochem 54:1467-1473, 1990.

Fishman, J.B.; Rubin, J.B.; Handrahan, J.V.; Connor, J.R.; and Fine, R.E. Receptor-mediated transcytosis of transferrin across the blood-brain barrier. J Neurosci Res 18:299-304, 1987.

Guillot, F.L., and Audus, K.L. Biochemistry of angiotensin peptide-mediated effects on fluid-phase endocytosis in brain microvessel endothelial cell monolayers. J Cereb Blood Flow Metab 10:827-834, 1990.

Guillot, F.L., and Audus, K.L. Angiotensin peptide regulation of bovine brain microvessel endothelial cell monolayers. J Cardiovasc Pharmacol 18:212218, 1991a.

Guillot, F.L., and Audus, K.L. Some characteristics of specific angiotensin II binding sites on bovine brain microvessel endothelial cell monolayers. Peptides 12:535-549, 1991 b.

Guillot, F.L.; Audus, K.L.; and Raub, T.J. Fluid-phase endocytosis by primary cultures of bovine brain microvessel endothelial cell monolayers. Microvasc Res 39:1-14, 1990.

Gulati, A.; Nath, C.; Shanker, K.; Srimal, R.C.; Dhawan, K.N.; and Bhargava, K.P. Effect of alcohols on the permeability of blood-brain barrier. Pharmacol Res Commun 17:85-93, 1985.

Jefferies, W.A.; Brandon, M.R.; Hunt, S.V.; Williams, A.F.; Gatter, K.C.; and Mason, D.Y. Transferrin receptor on endothelium of brain capillaries. Nature 312:162-163, 1984.

Keller, B.T., and Borchardt, R.T. Cultured bovine brain capillary endothelial cells (BBCEC) - a blood-brain barrier model for studying the binding and internalization of insulin and insulin-like growth factor 1. (Abstract 416.) Federations Proc 46:1997, 1987.

Keller, B.T.; Smith, K.R.; and Borchardt, R.T. Transport barriers to absorption of peptides. Pharm Weekbl [Sci] 10:38-39, 1988.

Kempski, 0.; Villacara, A.; Spatz, M.; Dodson, R.F.; Corn, C.; Merkel, N.; and Bembry, J. Cerebromicrovascular endothelial permeability: In vitro studies. Acta Neuropathol (Berl) 74:329-334, 1987.

Kumagai, A.K.; Eisenberg, J.B.; and Pardridge. W.M. Absorptive-mediated endocytosis of cationized albumin and a B-endorphin-cationized albumin chimeric peptide by isolated brain capillaries, J Biol Chem 262:15214-15219, 1987. 
Levin, V.A. Relationship of octanol/water partition coefficient and molecular weight to rat brain capillary permeability. J Med Chem 23:682-684, 1980.

Maxwell, K.; Berliner, J.A.; Bready, J.; and Cancilia, P.A. Stimulation of glucose analogue uptake by cerebral microvessel endothelial cells by a product released by astrocytes. J Neuropathol Exp Neurol 48:69-80, 1989.

Newton, C.R., and Raub, T.J. Characterization of the transferrin receptor in primary culture of bovine brain capillary endothelial cells. $J$ Cell Biol 107:770a, 1988.

Oldendoff, W.H. Brain uptake of radiolabeled amino acids, amines, and hexoses after arterial injection. Am J Physiol 221:1629-1639, 1971.

Oldendorf, W.H. Lipid solubility and drug penetration of the blood brain barrier. Proc Soc Exp Biol Med 147:813-816, 1974.

Panula, P.; Joo, F.; and Rechardt, L. Evidence for the presence of viable endothelial cells in cultures derived from dissociated rat brain. Experientia 34:95-97, 1978.

Pardridge, W.M. Brain metabolism: A perspective from the blood-brain barrier. Physiol Rev 63:1481-1 535, 1983.

Pardridge, W.M.; Eisenberg, J.; and Cefalu, W.T. Absence of albumin receptor on brain capillaries in vivo and in vitro. Am J Physiol 249:E264-E267. 1985.

Pardridge, W.M.; Triguero, D.; and Buciak, J. Transport of histone through the blood-brain barrier. J Pharmacol Exp Ther 251:821-826, 1989.

Raeissi, S., and Audus, K.L. In-vitro characterization of blood-brain barrier permeability to delta sleep-inducing peptide. J Pharmacol Pharm 41:848$852,1989$.

Rakic, L.M.; Zlokovic, B.V.; Davson, H.; Segal, M.B.; Begley. D.J.; Lipovac, M.N.; and Mitrovic, D.M. Chronic amphetamine intoxication and the bloodbrain barrier permeability to polar molecules studies in the vascularly perfused guinea pig brain. J Neural Sci 94:41-50, 1989.

Raub, T.J., and Audus, K.L. Adsorptive endocytosis and membrane recycling by cultivated primary bovine brain microvessel endothelial cell monolayers J Cell Sci 97:127-135, 1990.

Raub, T.J.; Kuentzel, S.L.; and Sawada, G.A. Characteristics of primary bovine cerebral microvessel endothelial cell monolayers on filters: Permeability and glial induced changes. J Cell Biol 109:315A, 1989.

Reardon, P.M., and Audus, K.L. Arginine-vasopressin distribution across the in vitro blood-brain barrier. Pharm Res 6:S-88. 1989.

Rim, S.; Audus. K.L.; and Borchardt. R.T. Relationship of octanol/buffer and octanol/water partition coefficients to transcellular diffusion across brain microvessel endothelial cell monolayers. Int J Pharm 32:79-84, 1986.

Rosenfeld, R.G.; Pham, H.; Keller, B.T.; Borchardt, R.T.; and Pardridge, W.M. Demonstration and structural comparison of receptors for insulin-like growth factor-I and -II (IGF-I and -II) in brain and blood-brain barrier. Biochem Biophys Res Commun 149:159-166.1987. 
Scriba, G.K.E., and Borchardt, R.T. Metabolism of catecholamine esters by cultured bovine brain microvessel endothelial cells. J Neurochem 53:610615,1989a.

Scriba, G.K.E.. and Borchardt, R.T. Metabolism of 1-methyl-4-phenyl-1,2,3,6tetrahydropyridine (MPTP) by bovine brain capillary endothelial cell monolayers. Brain Res 501:175-178, 1989b.

Shah, M.V.; Audus, K.L.; and Borchardt, R.T. The application of bovine brain microvessel endothelial-cell monolayers grown onto polycarbonate membranes in vitro to estimate the potential permeability of solutes through the blood-brain barrier. Pharm Res 6:624-627, 1989.

Shah, M.V., and Borchardt, R.T. Characterization of the nucleoside transport system in bovine brain microvessel endothelial cell (BBMEC) monolayers. Pharm Res 6:S-77, 1989.

Simionescu, N. The microvascular endothelium segmental differentiations; transcytosis; selective distribution of anionic sites. Adv Inflamm Res 1:61-70, 1979.

Smith, K.R., and Borchardt, R.T. Permeability and mechanism of albumin, cationized albumin, and glycosilated albumin transcellular transport across monolayers of cultured bovine brain capillary endothelial cells. Pharm Res 6:466-473, 1989.

Smith, K.R.; Kato, A.; and Borchardt, R.T. Characterization of specific receptors for atrial natriuretic factor on cultured bovine brain capillary endothelial cells. Biochem Biophys Res Commun 157:308-314, 1988.

Speth, R.C., and Harik, S.I. Angiotensin II receptor binding sites in brain microvessels. Proc Natl Acad Sci U S A 82:6340-6343, 1985.

Sudoh, T.; Kanagawa, K.; Minamiwa, N.; and Matsuo, H. A new natriuretic peptide in porcine brain. Nature 332:78-81, 1988.

Takakura, Y.; Audus, K.L.; and Borchardt, R.T. Blood-brain barrier: Transport studies in isolated brain capillaries and in cultured brain endothelial cells. In: August, J.T.; Anders, M.W.; and Murad, F., eds. Advances in Pharmacology. Vol. 22. Orlando, FL: Academic Press, 1991a. pp. 137-165.

Takakura, Y.; Kuentzel, S.L.; Raub, T.J.; Davies, A.; Baldwin, S.A.; and Borchardt, R.T. Hexose uptake in primary cultures of bovine brain microvessel endothelial cells. I. Basic characteristics and effects of Dglucose and insulin. Biochim Biophys Acta 1070:1-1 0, 1991c.

Takakura, Y.; Trammel, A.M.; Kuentzel, S.L.; Raub, T.J.; Davies, A.; Baldwin, S.A.; and Borchardt, R.T. Hexose uptake in primary cultures of bovine brain microvessel endothelial cells. II. Effects of conditioned media from astroglial and glioma cells. Biochim Biophys Acta 1070:11-1 9. 1991 b.

Thompson, S.E., and Audus, K.L. Aspects of leu-enkephalin transport and metabolism at the blood-brain barrier. Pharm Res 6:S175. 1989.

Trammel, A.M., and Borchardt, R.T. Choline transport in cultured brain microvessel endothelial cells. Pharm Res 4:S41. 1987. 
Trammel, A.M., and Borchardt, R.T. The effects of astrocytes and glioma cells on the permeability of cultured brain microvessel endothelial cells. Pharm Res 6:S-88, 1989.

Triguero, D.; Buciak, J.B.; Yang, J.; and Pardridge, W.M. Blood-brain barrier transport of cationized immunoglobulin G: Enhanced delivery compared to native protein. Proc Natl Acad Sci U S A 86:4761-4765, 1989.

van Bree, J.B.M.M.; Audus, K.L.; and Borchardt, R.T. Carrier-mediated transport of baclofen across monolayers of bovine brain endothelial cells in primary culture. Pharm Res 5:369-371, 1988.

van Bree, J.B.M.M.; de Bore, A.G.; Verhoef, J.C.; Danhof, M.; and Breimer, D.D. Transport of vasopressin fragments across the blood-brain barrier: In vitro studies using monolayer cultures of bovine brain endothelial cells. J Pharmacol Exp Ther 249:901-905. 1989.

van Houten, M., and Posner, B.I. Insulin binds to brain blood vessels in vivo. Nature 282:623-625, 1979.

Vinters, H.V.; Beck, D.W.; Bready, J.V.; Maxwell, K.; Berliner, J.A.; Hart, M.N.; and Cancilla, P.A. Uptake of glucose analogues into cultured cerebral microvessel endothelium. J Neuropathol Exp Neural 44:445-458, 1985.

Zlokovic, B.V.; Lipovac, M.N.; Begley, D.J.; Davson, H.; and Rakic, L. Transport of leucine-enkephalin across the blood-brain barrier in the perfused guinea pig brain. J Neurochem 49:310-315, 1987.

Zlokovic, B.V.; Susie, V.T.; Davson, H.; Begley, D.J.; Jankov, R.M.; Mitrovic, D.M.; and Lipovac, M.N. Saturable mechanism for delta sleep-inducing peptide (DSIP) at the blood-brain barrier of the vascularly perfused guinea pig brain. Peptides 10:249-254, 1989.

\section{ACKNOWLEDGMENTS}

The authors' research on bovine brain microvessel endothelial cells as a model of the BBB was supported by grants from the Upjohn Company, Merck Sharp \& Dohme-INTER, Corp., the American Heart Association, and the American Heart Association-Kansas Affiliate.

\section{AUTHORS}

Yoshinobu Takakura, Ph.D.

Assistant Professor

Kenneth L. Audus, Ph.D.

Associate Professor 
Address all correspondence to:

Ronald T. Borchardt, Ph.D.

Summerfield Professor and Chairman

Department of Pharmaceutical Chemistry

University of Kansas School of Pharmacy

Malott Hall, Room 3006

Lawrence, KS 66045 